\title{
1 Letter:
}

\section{Equitable mitigation to achieve the Paris Agreement goals}

4 Yann Robiou du Pont ${ }^{1 *}$, M. Louise Jeffery ${ }^{2}$, Johannes Gütschow ${ }^{2}$, Joeri Rogelj $^{3,4}$, Peter

5 Christoff $^{5}$, Malte Meinshausen ${ }^{1,2}$

6

$7{ }^{1}$ Australian-German Climate \& Energy College, University of Melbourne, Parkville 3010,

$8 \quad$ Victoria, Australia.

$9{ }^{2}$ Potsdam Institute for Climate Impact Research (PIK), Telegraphenberg, 14412 Potsdam,

10 Germany

$11{ }^{3}$ Energy Program, International Institute for Applied Systems Analysis (IIASA) Schlossplatz 1,

12 A-2361 Laxenburg, Austria.

$13{ }^{4}$ Institute for Atmospheric and Climate Science, ETH Zurich, 8092 Zurich, Switzerland

$14{ }^{5}$ School of Geography, University of Melbourne, Parkville 3010, Victoria, Australia.

15 *Corresponding author: Yann Robiou du Pont, yann.rdp@climate-energy-college.org

16 


\section{Manuscript.}

18

19

20

21

22 allocate their emissions dynamically to countries according to five equity approaches. At the

23 national level, China's Nationally Determined Contribution (NDC) is weaker than any of the five

24 equity approaches suggests, India's NDC is aligned with two, and the EU's and the USA's with

25 three. Most developing countries' conditional (Intended) NDCs (INDCs) are more ambitious

26 than the average of the five equity approaches under the $2^{\circ} \mathrm{C}$ goal. If the $\mathrm{G} 8$ and China adopt the

27 average of the five approaches, the gap between conditional INDCs and $2^{\circ} \mathrm{C}$ consistent pathways

28 could be closed. Equitable, cost-optimal, achievement of the $1.5^{\circ} \mathrm{C}$ target allocates the $\mathrm{G} 8$ and

29 China combined $21 \%$ emissions lower in 2030 (relative to 2010 levels) than for $2^{\circ} \mathrm{C}$, and $39 \%$

30 lower for remaining countries. Equitably limiting warming to $1.5^{\circ} \mathrm{C}$ rather than $2{ }^{\circ} \mathrm{C}$ requires that

31 individual countries achieve mitigations milestones, such as peaking or reaching net-zero

32 emissions, around a decade earlier. 
35 To achieve its global mitigation objectives (Fig. 1a), the Paris Agreement binds countries to 36 periodically take stock of collective progress "in light of equity and the best available science"1, 37 starting in 2018. The Agreement did not indicate national mitigation targets aligned with the 38 long-term goals and "notes with concern that the estimated aggregate greenhouse gas emissions 39 levels in 2025 and 2030 resulting from the intended nationally determined contributions do not 40 fall within cost-optimal $2^{\circ} \mathrm{C}$ scenarios" ${ }^{\prime}$. Indeed, the current "bottom-up" situation, whereby 41 countries determine their own mitigation targets, results in projected annual global emissions of $4252.5 \mathrm{GtCO}_{2} \mathrm{eq}$ (ref. 2) in 2030 (average of $49.4 \mathrm{GtCO}_{2} \mathrm{eq}$ and $55.6 \mathrm{GtCO}_{2} \mathrm{eq}$, respectively the 43 'high-ambition' and 'low-ambition' estimates of ref. 3, SAR GWP-100, Methods), inconsistent 44 with Integrated Assessment Models' (IAMs) cost-optimal trajectories to $2^{\circ} \mathrm{C}$ or $1.5^{\circ} \mathrm{C}$ (ref. 4 , 45 Fig. 1a). In 1992, under the United Framework Convention on Climate Change (UNFCCC), all countries

47 agreed to pursue mitigation efforts according to their "Common but Differentiated

48 Responsibilities and Respective Capabilities"5 (CBDR-RC), with efforts differentiated between

49 developed (Annex I) and developing countries. The Paris Agreement moved to a sliding scale of 50 self-differentiation on emissions mitigation. While co-benefits and self-interest can drive rapid 51 mitigation actions ${ }^{6}$, current contributions are insufficient to match the ambition of the Paris 52 Agreement. Therefore, equity is still central for the ratcheting process and when discussing the 53 adequate magnitude of climate finance and support ${ }^{7}$. All ratifying Parties must communicate 54 successive NDCs that represent a progression and reflect the "highest possible ambition" in 3 
55 relation to their CBDR-RC. The Paris Agreement still invites developed countries, without

56 naming them ${ }^{8}$, to take the lead in reducing economy-wide emissions and mobilizing climate

57 finance.

58 Historically, few countries have indicated which guiding principle ${ }^{9-11}$ or formula ${ }^{12}$ could be used

59 to ensure equitable mitigation contributions. Instead, most countries merely declared their

60 INDCs to be "fair and ambitious", either explicitly (e.g. India and the USA ${ }^{13}$ ) or implicitly by

61 stating their contribution. Here we inform the question of fairness by quantifying national

62 emissions allocations using five 'equity approaches'. Unlike most earlier studies, we use a

63 methodology that aligns aggregate emissions allocations with IAM global emissions scenarios

64 that are consistent with the Paris Agreement's long-term goals.

65 Several studies have modelled equity principles to allocate $2^{\circ} \mathrm{C}$-consistent emissions scenarios

66 across countries ${ }^{12,14-24}$. The IPCC's Fifth Assessment Report (IPCC-AR5) grouped the

67 distributive justice concepts of over 40 studies in five equity categories ${ }^{18,25}$ (Table 1). Most of

68 these studies allocate emissions of different global scenarios that are not always cost-optimal;

69 comparing allocations at a specific point in time is therefore difficult. More recent studies

70 developed frameworks that allocate emissions from a unique global scenario across countries

71 following multiple equity approaches, and derived national GHG (ref. 21,24) or $\mathrm{CO}_{2}$ only ${ }^{20,23}$

72 scenarios consistent with the $2^{\circ} \mathrm{C}$ limit. However, national equitable emissions allocations

73 consistent with the $1.5^{\circ} \mathrm{C}$ goal have not yet been assessed in the literature. 
74 We use the five IPCC-AR5 equity categories ${ }^{25}$ to define five equity approaches ${ }^{24}$ (Table 1).

75 These allocation approaches are applied to cost-optimal scenarios selected from the database

76 accompanying the IPCC-AR5 and ref. 26 that have net-zero emissions by 2100 and at least a

77 likely (>66\%) chance to limit warming to $2^{\circ} \mathrm{C}$ (Methods). We explore five 'sets' of GHG

78 emissions scenarios based on this selection (Table 1): (i) 32 scenarios peaking by 2020 (' $2{ }^{\circ} \mathrm{C}$ -

79 pre2020peak'), (ii) 39 peaking by 2020 with a more likely than not $(>50 \%)$ chance to return to

$80 \quad 1.5^{\circ} \mathrm{C}$ in 2100 (' $1.5^{\circ} \mathrm{C}$-pre2020peak'), (iii) 6 scenarios peaking in 2030 (' $2{ }^{\circ} \mathrm{C}-2030$ peak'), (iv) a

81 custom ' $2{ }^{\circ} \mathrm{C}$-statedINDCs' scenario with interpolated emissions between 2030 pledged INDC

82 levels ${ }^{3}$ and, from 2050 onwards, the average of the ' $2{ }^{\circ} \mathrm{C}-2030$ peak'scenarios, and (v) a ' $2{ }^{\circ} \mathrm{C}$ -

83 fairINDCs' scenario equal to global scenario (iv) but with allocations starting in 2010 (Fig. 1a).

84 The ' $2{ }^{\circ} \mathrm{C}-2030$ peak' scenarios are only loosely consistent with the Paris Agreement (Methods).

85 Emissions allocations of all sets start in 2010, except for (iv), which starts in 2030 at national

86 INDCs levels.

87 [TABLE 1]

88 The ' $2{ }^{\circ} \mathrm{C}$-pre2020peak' scenario set has a 2030 average of $39.7 \mathrm{GtCO}_{2} \mathrm{eq}$, similar to the Paris

89 decision indicative target of $40 \mathrm{GtCO}_{2} \mathrm{eq}$, and becomes net-zero as early as 2080 (Fig. 1a). The

90 ' $1.5^{\circ} \mathrm{C}$-pre2020peak' set averages at $32.6 \mathrm{GtCO}_{2}$ eq in 2030 and becomes negative between 2059

91 and 2087. Average annual global emissions reduction rates over the 2030-2050 period, as a

92 fraction of 2010 levels, are 1.6\%/y for early-action ' $2{ }^{\circ} \mathrm{C}$-pre2020peak' scenarios (reaching

$932.1 \% / y$ in 2025 ), $2.2 \% / y$ for $1.5^{\circ} \mathrm{C}$ scenarios (reaching $2.3 \% / y$ in 2039 ), and $3.2 \% / y$ for delayed-

94 action ' $2{ }^{\circ} \mathrm{C}-2030$ peak' scenarios (reaching 3.5\%/y from 2040 to 2050 ). 
95 The selected cost-optimal scenarios rely on the IAM's assumptions of harmonized international 96 policies and emissions trading systems that are currently not in place. However, the Paris

97 Agreement has recognized the voluntary "use of internationally transferred mitigation outcomes

98 towards nationally determined contributions". The emissions allocations determined here could

99 be met through a combination of domestic mitigation, internationally traded emissions

100 mitigation $^{1}$ and international financial contributions toward global mitigation ${ }^{24}$. Under any of our

101 modelled equity approaches, the national emissions scenarios are not cost-optimal if applied

102 domestically. However, they are consistent with a global cost-optimal scenario if countries

103 choose the right mix of domestic mitigation and transfer of support for additional mitigation

104 elsewhere. National mitigation costs are allocated indirectly through the allocation of emissions

105 allowances. A fair distribution of mitigation costs could be used to derive equitable emissions

106 allocation when comprehensive national-level mitigation cost estimates are available.

107 We allocate to all countries GHG emissions scenarios that add up, under each of the five equity

108 approaches (Supplementary Tables), to global cost-optimal IAM scenarios - excluding emissions

109 from Land Use, Land-Use Change and Forestry (LULUCF), and international shipping and

110 aviation (Methods).

111 At the regional level (Fig. 1c-1), Middle East and Africa's aggregated (I)NDCs are consistent

112 with all approaches except the CER under all scenario-sets. Asia's aggregated (I)NDCs are not

113 consistent with any allocation under early-action scenarios, while the OECD's are consistent

114 with the GDR and CER under the ' $2{ }^{\circ} \mathrm{C}$-pre2020peak' and with none under ' $1.5^{\circ} \mathrm{C}$-pre2020peak'. 
115 Only the aggregated (I)NDCs of the Middle East and Africa are consistent with some $1.5^{\circ} \mathrm{C}$

116 allocations (with great disparities at the sub-regional level, Supplementary Discussion).

117 At the national level (Fig. 1c-g), all equity approaches require China's emissions to peak earlier 118 and lower than its current NDC. The USA's and the EU's NDCs are in line with the CER

119 allocation and the higher end of the ' $2{ }^{\circ} \mathrm{C}$-pre2020peak' range under the GDR or EPC allocations.

120 India's NDC is consistent with the CPC and EPC allocations of ' $2{ }^{\circ} \mathrm{C}$-pre2020peak' scenarios,

121 and the CPC allocation averaged over the ' $1.5^{\circ} \mathrm{C}$-pre2020peak' scenarios lies within the NDC

122 assessment's uncertainty range (Fig. 1b, other countries in Supplementary Tables and provided at

123 at: www.paris-equity-check.org).

124 [FIGURE 1]

125 Combining multiple visions of equity - using weighting factors ${ }^{20}$ or a leadership based 126 approach $^{22}$ - is not necessarily equitable by design but can represent a political compromise ${ }^{20}$,

127 and is useful to compare national allocations under different global goals or scenarios sets. The

128 fairness of the CER, or 'grandfathering', approach is criticized in the literature ${ }^{23,27}$ and not

129 supported as such by any Party. However, we include CER in the average because it represents

130 one of the five IPCC equity categories, stressing national circumstances regarding current

131 emissions levels, and is implicitly followed by many of the developed countries ${ }^{23,24}$. The average

132 allocation of the EU and the USA becomes negative close to mid-century under both the ' $1.5^{\circ} \mathrm{C}$ -

133 pre2020peak' and ' $2{ }^{\circ} \mathrm{C}$-pre2020peak' sets. China's average allocation becomes negative 20

134 years later, and India's only at the end of the century. 
136 Recent studies using alternative implementation ${ }^{24}$ or modelling ${ }^{21,22}$ of similar equity approaches 137 towards $2^{\circ} \mathrm{C}$ find significant differences in some national emissions allocations, but generally 138 reach similar conclusions (Supplementary Discussion). Overall, literature focusing on $\mathrm{CO}_{2}$ 139 emissions de-facto ignores other $\mathrm{GHG}^{20,23}$, and often allocates carbon budgets ${ }^{20}$ impossible to 140 compare with single-year (I)NDCs.

141 Reflecting the global scenarios, equitable national allocations towards $1.5^{\circ} \mathrm{C}$ require earlier 142 mitigation than for $2^{\circ} \mathrm{C}$ (Fig. 2, results per-approach in the Supplementary Discussion). To 143 achieve the $1.5^{\circ} \mathrm{C}$ goal 'major economies' (G8 and China as a group) need to lower their 2030 144 emissions targets by an additional 21 percent-points relative to 2010 emissions, compared to the 145 ' $2{ }^{\circ} \mathrm{C}$-pre2020peak' case, and other countries ('other economies') altogether by 39 additional 146 percentage-points (Fig. 2a). However, increasing current (I)NDCs by these additional 147 percentages would not result in fair contributions towards the $1.5^{\circ} \mathrm{C}$ goal. Indeed, the aggregated 148 (I)NDCs of the 'major economies' should already be 39 percentage-points more stringent than 149 they currently are to be in line with their averaged allocation under the ' $2{ }^{\circ} \mathrm{C}$-pre2020peak' case 150 (Fig. 2b). In contrast, the aggregated (I)NDCs of the 'other economies' are only 8 percentage151 points above ' $2{ }^{\circ} \mathrm{C}$-pre2020peak' average allocations. Consequently, pledges in line with the $1521.5^{\circ} \mathrm{C}$ goal should be respectively 60 and 46 percentage-points more stringent than current 153 (I)NDCs for 'major economies' and 'other economies' respectively (Fig. 2c). 
154 In order to compare the relative fairness of (I)NDCs under the current global ambition (52.5

$155 \mathrm{GtCO}_{2} \mathrm{eq}$ for 2030$)$, we compare (I)NDCs (' $2{ }^{\circ} \mathrm{C}$-statedINDCs' set) with the ' $2{ }^{\circ} \mathrm{C}$-fairINDCs'

156 allocations (Fig. 2d). We find that the (I)NDCs of 'other economies', of the USA, and of the EU

157 are more ambitious or aligned with their average allocation under current international 2030-

158 ambition, while the (I)NDCs of Canada, of Japan, and especially of Russia and of China are

159 substantially less ambitious.

160 Emissions budgets and timing for peaking or net-zero emissions may constitute more easily

161 actionable targets than temperature goals ${ }^{28}$. Figures $2 \mathrm{e}-\mathrm{g}$ compare the average timing when

162 emissions allocations peak or reach net-zero under the five equity approaches for ' $1.5^{\circ} \mathrm{C}$ -

163 pre2020peak' and ' $2{ }^{\circ} \mathrm{C}$-pre2020peak'. Net-zero emissions are allocated five years earlier

164 towards $1.5^{\circ} \mathrm{C}$ for developing countries, and ten years earlier for developed countries (i.e. around

165 2055-2060). Developing countries' allocations peak about ten years earlier and up to $40 \%$ lower

166 towards $1.5^{\circ} \mathrm{C}$ than $2^{\circ} \mathrm{C}$, which implies lower domestic emissions or lower revenues from

167 emissions-trading. Overall, aiming at $1.5^{\circ} \mathrm{C}$ rather than towards $2^{\circ} \mathrm{C}$ requires earlier but not

168 faster or deeper mitigation at the national level (Supplementary Discussion).

169 [FIGURE 2]

170 The lower emissions-end of our (I)NDC quantification ('high-ambition' target) is set by the

171 conditional targets and sometimes by the quantification uncertainty. Hence, in most countries,

172 these 'high-ambition' targets have implicitly been identified as feasible. The implementation of

173 these 'high-ambition' (I)NDCs ${ }^{3}$ would lead to 2030 emissions of $48.9 \mathrm{GtCO}_{2} \mathrm{eq}$ and leave an 8.8 
$174 \mathrm{GtCO}_{2}$ eq gap with the average of ' $2{ }^{\circ} \mathrm{C}$-pre2020peak' scenarios and a $20.4 \mathrm{GtCO}_{2}$ eq gap with the

175 '1.5 $5^{\circ} \mathrm{C}$-pre2020peak' average (excluding LULUCF and bunkers emissions, Methods). The

176 aggregated 'high-ambition' (I)NDCs of 'other economies' are collectively slightly more

177 ambitious than the average of their allocations (Fig. 3 and Supplementary Discussion), although

178 some individual (I)NDCs are less ambitious (e.g. Iran, Saudi-Arabia and Turkey). Therefore, the

179 'other economies' altogether could meet their average 'fair' allocation by increasing their current 180 unconditional contribution to the aggregate level of their conditional (I)NDCs. The average 'fair' 181 allocations of 'major economies' is $9.6 \mathrm{GtCO}_{2}$ eq below their current aggregated 'high-ambition' 182 (I)NDCs. Put simply, the average 'fair' allocation of 'major economies' alone closes the global 1832030 mitigation gap to $2^{\circ} \mathrm{C}$, provided that other countries achieve their 'high-ambition' (I)NDC 184 targets. Closing the 2030 gap to average ' $1.5^{\circ} \mathrm{C}$-pre2020peak' scenarios requires most countries 185 to increase their ambition beyond their current conditional (I)NDCs.

186 [FIGURE 3]

187 Current aggregate (I)NDCs fall substantially short of meeting either the $2^{\circ} \mathrm{C}$ or $1.5^{\circ} \mathrm{C}$ goals ${ }^{2,4}$. 188 The ratchet mechanisms established by the Paris Agreement ${ }^{1}$ need to achieve an additional 13 $189 \mathrm{GtCO}_{2} \mathrm{eq}$ reduction in 2030 to align with $2^{\circ} \mathrm{C}$ cost-optimal scenarios, and $20 \mathrm{GtCO}_{2}$ eq for $1.5^{\circ} \mathrm{C}$ 190 (Fig. 1a). We derived 'Equitably Determined Contributions' consistent with the five IPCC equity 191 approaches towards $2^{\circ} \mathrm{C}$ or $1.5^{\circ} \mathrm{C}$ goals (Supplementary Tables). Averaging across the five 192 concepts of equity assigns the effort, beyond current conditional (I)NDCs, required for the $2^{\circ} \mathrm{C}$ 193 goal to the G8 and China. Equitably meeting the $1.5^{\circ} \mathrm{C}$ goal, and avoiding the additional climate 194 impacts of a $2^{\circ} \mathrm{C}$ warmer world ${ }^{29}$, means that almost all national contributions should be 10 
195 enhanced substantially, with key milestones, such as peaking or reaching net-zero emissions, 196 brought forward by a decade or more. 
198 Supplementary information is available in the online version of the paper. Correspondence

199 should be addressed to Y.R.d.P.. The equitable emissions allocations of all countries are included

200 in the Supplementary Tables in the online version of the paper and can be visualized at:

201 www.paris-equity-check.org.

\section{Acknowledgments}

203 We gratefully acknowledge the work of modellers behind the IPCC-AR5 emissions scenarios.

204 M. Meinshausen is supported by the Australian Research Council (ARC) Future Fellowship

205 (grant number FT130100809). Deep thanks to Anita Talberg for her comments on the

206 manuscript.

\section{Author contributions}

208 All authors contributed to discussing the results and writing the manuscript. Y.R.d.P. led the 209 study and performed the calculations. M.L.J. modelled the GDR approach. J.G. downscaled to 210 the national level global RCP8.5 emissions scenarios using SSP data. Y.R.d.P. and M.M.

211 suggested the study. J.G., M.L.J. and M.M. updated and managed the composite PRIMAP 212 database.

\section{Competing financial interests}

214 The authors declare no competing financial interests. 
217 five equity principles compared to current pledges. a, IAM scenarios consistent with the Paris

218 Agreement under ' $1.5^{\circ} \mathrm{C}$-pre2020peak' (red), ' $2{ }^{\circ} \mathrm{C}$-pre2020peak' (blue) and ' $2{ }^{\circ} \mathrm{C}-2030$ peak'

219 cases (purple), and their averages (thicker lines). Scenarios consistent with the 2030 Paris

220 decision target (green circles) are more opaque. b, Comparison with IPCC-AR5 database

221 scenarios (grey lines). c-g, National emissions allocations excluding LULUCF compared to

222 (I)NDCs (black circles). Coloured patches and lines show allocation ranges of global ' $2{ }^{\circ} \mathrm{C}$ -

223 pre2020peak' scenarios, and averages over the range of global ' $1.5^{\circ} \mathrm{C}$-pre2020peak' scenarios,

224 respectively. h-l, Regionally aggregated 2030 allocations and (I)NDCs.

225

226

227

228

229

230

231

232

233

234

Figure 2 | Comparisons of national emissions change under different global goals. a-d, Relative changes between ' $1.5^{\circ} \mathrm{C}$-pre2020peak', ' $2{ }^{\circ} \mathrm{C}$-pre2020peak', ' $2{ }^{\circ} \mathrm{C}$-statedINDC' and ' $2{ }^{\circ} \mathrm{C}$-fairINDC' cases over the 2010-2030 period (excluding LULUCF). e-f, Comparison of timing of first net-zero emissions and peaking national emissions averaged over the five equity approaches for the ' $1.5^{\circ} \mathrm{C}$-pre2020peak' and ' $2{ }^{\circ} \mathrm{C}$-pre2020peak' cases. g, Average of peaking emissions levels versus average peaking emissions years for ' $1.5^{\circ} \mathrm{C}$-pre 2020 peak' and ' $2{ }^{\circ} \mathrm{C}$ pre2020peak' cases. Disk sizes are proportional to 2010 emissions levels. Colours indicate world regions. G8+China (larger disk) and the rest of the world (smaller disk) are shown in grey.

\section{Figure 3 | Gaps between equitable mitigation allocations and conditional (I)NDCs in 2030.}

Countries following individual approaches (tip of coloured patches), or their average (black 
235 lines) under the $2^{\circ} \mathrm{C}$ (panel a) or $1.5^{\circ} \mathrm{C}$ goals (panel b), reduce or increase the projected 2030 236 global emissions levels (excluding LULUCF and bunker emissions) compared to aggregated 237 conditional (I)NDCs. Countries are sorted left to right in decreasing order of 2010 emissions 238 (proportional to bar width). The global gaps (grey arrow) between current aggregated conditional 239 (I)NDCs and the average scenarios consistent with the Paris $2^{\circ} \mathrm{C}$ or $1.5^{\circ} \mathrm{C}$ goals (grey bar) are 240 shown in each panel. 
242 Tables

243 Table 1 | Allocation approaches and global scenario set descriptions. The allocation

244 framework modelling and parameterization follow those of ref. 24. More details on the scenario

245 selection in the Supplementary Methods.

\begin{tabular}{|c|c|c|c|}
\hline Allocation name & Allocation type & IPCC category & Allocation characteristics \\
\hline CAP & Capability & Capability & High mitigation for countries with high GDP per capita. \\
\hline EPC & Equal per capita & Equality & Convergence towards equal annual emissions per person. \\
\hline GDR & $\begin{array}{l}\text { Greenhouse } \\
\text { Development } \\
\text { Rights }\end{array}$ & $\begin{array}{l}\text { Responsibility- } \\
\text { capability-need }\end{array}$ & $\begin{array}{l}\text { High mitigation for countries with high GDP per capita and high } \\
\text { historical per capita emissions. }\end{array}$ \\
\hline CPC & $\begin{array}{l}\text { Equal cumulative } \\
\text { per capita }\end{array}$ & $\begin{array}{l}\text { Equal cumulative } \\
\text { per capita }\end{array}$ & Populations with high historical emissions have low allocations. \\
\hline CER & $\begin{array}{l}\text { Constant emissions } \\
\text { ratio }\end{array}$ & $\begin{array}{l}\text { Staged } \\
\text { approaches }\end{array}$ & Maintains current emissions ratios. \\
\hline Scenario set & Scenario type & IPCC category & Scenarios characteristics \\
\hline $1.5^{\circ} \mathrm{C}$-pre2020peak & $1.5^{\circ} \mathrm{C}$ scenarios & $39 \mathrm{P} 1 \mathrm{P} 2$ scenarios & $\begin{array}{l}\text { More likely than not (>50\%) chance to return to } 1.5^{\circ} \mathrm{C} \text { in } 2100 \text {. } \\
\text { Global emissions peaking by } 2020 \text {. National emissions allocated } \\
\text { from } 2010 \text { onwards. }\end{array}$ \\
\hline $2^{\circ} \mathrm{C}$-pre2020peak & $\begin{array}{l}2^{\circ} \mathrm{C} \text { early action } \\
\text { scenarios }\end{array}$ & $32 \mathrm{P} 1 \mathrm{P} 2$ scenarios & $\begin{array}{l}\text { Likely (>66\%) chance to stay below } 2^{\circ} \mathrm{C} \text { by } 2100 \text {. Global } \\
\text { emissions peaking by } 2020 \text {. National emissions allocated from } \\
2010 \text { onwards. }\end{array}$ \\
\hline $2^{\circ} \mathrm{C}-2030$ peak & $\begin{array}{l}2^{\circ} \mathrm{C} \text { delayed action } \\
\text { scenario }\end{array}$ & $6 \mathrm{P} 3$ scenarios & $\begin{array}{l}\text { Likely ( }>66 \% \text { ) chance to stay below } 2^{\circ} \mathrm{C} \text { by } 2100 \text {. Global } \\
\text { emissions peaking in } 2030 \text {. National emissions allocated from } \\
2010 \text { onwards. }\end{array}$ \\
\hline $2^{\circ} \mathrm{C}$-statedINDC & $\begin{array}{l}2^{\circ} \mathrm{C} \text { delayed action } \\
\text { scenario }\end{array}$ & $\begin{array}{l}1 \mathrm{P} 3 \text { custom } \\
\text { scenario }\end{array}$ & $\begin{array}{l}\text { De-facto likely (>66\%) chance to stay below } 2^{\circ} \mathrm{C} \text { by } 2100 \text {. } \\
\text { Global emissions peaking in } 2030 \text {. National emissions allocated } \\
\text { from } 2030 \text { (I)NDC levels onwards. }\end{array}$ \\
\hline $2^{\circ} \mathrm{C}$-fairINDC & $\begin{array}{l}2^{\circ} \mathrm{C} \text { delayed action } \\
\text { scenario }\end{array}$ & $\begin{array}{l}1 \mathrm{P} 3 \text { custom } \\
\text { scenario }\end{array}$ & $\begin{array}{l}\text { De-facto likely ( }>66 \% \text { ) chance to stay below } 2^{\circ} \mathrm{C} \text { by } 2100 \text {. } \\
\text { Global emissions peaking in } 2030 \text {. National emissions allocated } \\
\text { from } 2010 \text { onwards. }\end{array}$ \\
\hline
\end{tabular}

247 Table 2 | Mitigation targets, timing of peaking and net-zero emissions, and emissions

248 budgets of selected countries for the ' $1.5^{\circ} \mathrm{C}$-pre2020peak' and ' $2^{\circ} \mathrm{C}$-pre 2020 peak' cases,

249 averaged over the five equity allocations. Target ranges indicate the extrema across the five 
250 approaches' averages. Emissions from LULUCF and bunkers are excluded. Data for all countries

251 available in the Supplementary Tables. Emissions budgets are accounted from 2010.

\begin{tabular}{|c|c|c|c|c|c|c|c|c|c|}
\hline \multirow{3}{*}{$\begin{array}{r}\text { Country } \\
\text { World (no } \\
\text { bunkers) }\end{array}$} & \multirow{3}{*}{$\begin{array}{r}\text { Goal } \\
2^{\circ} \mathrm{C} \\
1.5^{\circ}\end{array}$} & \multicolumn{2}{|c|}{$\begin{array}{l}2030 \text { change to } \\
2010 \text { levels (in \%) }\end{array}$} & \multicolumn{2}{|c|}{$\begin{array}{c}2050 \text { change to } 2010 \\
\text { levels (in \%) }\end{array}$} & $\begin{array}{l}\text { Peaking } \\
\text { year }\end{array}$ & $\begin{array}{l}\text { Net-zero } \\
\text { year }\end{array}$ & $\begin{array}{l}\text { Budget to } 2050 \\
\text { in GtCO2eq }\end{array}$ & $\begin{array}{l}\text { Budget to } 2100 \\
\text { in GtCO2eq }\end{array}$ \\
\hline & & -5 & & -47 & & $\begin{array}{r}2020 \\
\text { Immediat }\end{array}$ & 2082 & 1523 & 1749 \\
\hline & & -33 & & -78 & & & 2075 & 1134 & 1156 \\
\hline & & & & & & Immediat & & & \\
\hline China & $2^{\circ} \mathrm{C}$ & -27 & [-59 to 6$]$ & -70 & {$[-95$ to -44$]$} & e & 2075 & 329 & 345 \\
\hline сита & $\begin{array}{r}1.5^{\circ} \\
\mathrm{C}\end{array}$ & -48 & {$[-71$ to -19$]$} & -88 & [-102 to -76$]$ & Immediat & 2065 & 254 & 237 \\
\hline & & & & & & Immediat & & & \\
\hline USA & $2^{\circ} \mathrm{C}$ & -44 & [-66 to -5$]$ & -89 & [-119 to -47$]$ & e & 2067 & 154 & 104 \\
\hline & $\mathrm{C}$ & -64 & [-80 to -33$]$ & -109 & [-144 to -78$]$ & $\mathrm{e}$ & 2057 & 109 & 57 \\
\hline EU & $2^{\circ} \mathrm{C}$ & -38 & [-62 to -5$]$ & -86 & [-122 to -47$]$ & $\begin{array}{r}\text { Immediat } \\
e \\
\text { Immediat }\end{array}$ & 2068 & 114 & 94 \\
\hline & $\mathrm{C}$ & -62 & [-84 to -33$]$ & -106 & [-149 to -78$]$ & $\mathrm{e}$ & 2057 & 80 & 54 \\
\hline Indi & $2^{\circ} \mathrm{C}$ & 72 & [-5 to 155$]$ & 40 & [-47 to 152$]$ & 2033 & 2087 & 162 & 236 \\
\hline India & $\begin{array}{r}1.5^{\circ} \\
\mathrm{C}\end{array}$ & 30 & {$[-33$ to 102$]$} & -24 & {$[-78$ to 63$]$} & 2022 & 2081 & 122 & 161 \\
\hline
\end{tabular}




\section{References}

254 1. UNFCCC. Adoption of the Paris Agreement. 21932, (2015).

2552 2. UNFCCC. Synthesis report on the aggregate effect of the intended nationally determined 256 contributions - Technical Annex. FCCC/CP, (2015).

257 3. Meinshausen, M. Climate College - INDC Factsheets. (2015). Available at:

258 http://climatecollege.unimelb.edu.au/indc-factsheets/.

2594 Rogelj, J. et al. Paris Agreement climate proposals need a boost to keep warming well below $2^{\circ}$

260 C. Nature 534, 631-639 (2016).

$2615 . \quad$ UNFCCC. United Nations Framework Convention on Climate Change. Review of European 262 Community and International Environmental Law 1, (1992).

263 6. Averchenkova, A., Stern, N. \& Zenghelis, D. Taming the beasts of ' burden-sharing ': an analysis 264 of equitable mitigation actions and approaches to 2030 mitigation pledges. (2014).

2657 Mace, M. J. Mitigation Commitments Under the Paris Agreement and the Way Forward. Clim. 266 Law 6, 21-39 (2016).

267 8. Voigt, C. \& Ferreira, F. Differentiation in the Paris Agreement. Clim. Law 6, 58-74 (2016).

268 9. Commission of the European Communities. Impact Assessment: Document accompanying the 269 Package of Implementation measures for the EU's objectives on climate change and renewable energy 270 for 2020 Proposals. (2008).

271 10. Japan. Submission by Japan - Information, views and proposals on matters related to the work 272 of Ad Hoc Working Group on the Durban Platform for Enhanced Action (ADP) Workstream 1. (2014).

273 11. Nepal on Behalf of the Least Developed Countries Group. Submission by the Nepal on behalf of 274 the Least Developed Countries Group : Views and proposals on the work of the Ad Hoc Working Group 275 on the Durban Platform for Enhanced Action ( ADP ). (2014).

276 12. Winkler, H. et al. Equitable access to sustainable development: Contribution to the body of 277 scientific knowledge. (2011).

278 13. UNFCCC. Submitted INDCs. (2016). Available at: http://www4.unfccc.int/submissions/indc/. 279 (Accessed: 5th February 2016)

280 14. Baer, P., Fieldman, G., Athanasiou, T. \& Kartha, S. Greenhouse Development Rights: towards an 281 equitable framework for global climate policy. Cambridge Rev. Int. Aff. 21, 649-669 (2008).

282 15. den Elzen, M., Höhne, N. \& Moltmann, S. The Triptych approach revisited: A staged sectoral 283 approach for climate mitigation. Energy Policy 36, 1107-1124 (2008). 
284 16. Jacoby, H. D., Babiker, M. H., Paltsev, S. \& Reilly, J. M. Sharing the Burden of GHG Reductions. 285 MIT Joint Program on the Science and Policy of Global Change (2008).

286 17. Nabel, J. E. M. S. et al. Decision support for international climate policy - The PRIMAP emission 287 module. Environ. Model. Softw. 26, 1419-1433 (2011).

288 18. Höhne, N., den Elzen, M. \& Escalante, D. Regional GHG reduction targets based on effort 289 sharing: a comparison of studies. Clim. Policy 14, 122-147 (2013).

290 19. Tavoni, M. et al. Post-2020 climate agreements in the major economies assessed in the light of 291 global models. Nat. Clim. Chang. 5, 119-126 (2014).

292 20. Raupach, M. R. et al. Sharing a quota on cumulative carbon emissions. Nat. Clim. Chang. 4, 873293879 (2014).

294 21. Pan, X., Teng, F., Tian, Y. \& Wang, G. Countries' emission allowances towards the low-carbon 295 world: A consistent study. Appl. Energy 155, 218-228 (2015).

$29622 . \quad$ Meinshausen, M. et al. National post-2020 greenhouse gas targets and diversity-aware 297 leadership. Nat. Clim. Chang. 1-10 (2015). doi:10.1038/nclimate2826

298 23. Peters, G. P., Andrew, R. M., Solomon, S. \& Friedlingstein, P. Measuring a fair and ambitious 299 climate agreement using cumulative emissions. Environ. Res. Lett. 10, 105004 (2015).

300 24. Robiou du Pont, Y., Jeffery, M. L., Gütschow, J., Christoff, P. \& Meinshausen, M. National 301 contributions for decarbonizing the world economy in line with the G7 agreement. Environ. Res. Lett. 30211,54005 (2016).

303 25. Edenhofer, O. et al. IPCC, 2014: Climate Change 2014: Mitigation of Climate Change. 304 Contribution of Working Group III to the Fifth Assessment Report of the Intergovernmental Panel on 305 Climate Change. (2014).

$30626 . \quad$ Rogelj, J. et al. Energy system transformations for limiting end-of-century warming to below 1.5 $307 \quad{ }^{\circ} \mathrm{C}$. Nat. Clim. Chang. 5, 519-527 (2015).

308 27. Caney, S. Justice and the distribution of greenhouse gas emissions. J. Glob. Ethics 5, 125-146 309 (2009).

310 28. Geden, O. An actionable climate target. Nat. Geosci. 2-4 (2016). doi:10.1038/ngeo2699

$31129 . \quad$ Schleussner, C.-F. et al. Differential climate impacts for policy-relevant limits to global warming: 312 the case of $1.5^{\circ} \mathrm{C}$ and $2{ }^{\circ} \mathrm{C}$. Earth Syst. Dyn. Discuss. 6, 2447-2505 (2016). 


\section{Methods:}

\section{Scenario selection}

315 We selected global emissions scenarios from the IPCC-AR5 database (hosted at the International

316 Institute for Applied Systems Analysis and available at: tntcat.iiasa.ac.at/AR5DB/) and ref. 26

317 that feature negative GHG emissions by the end of the century and a chance equal to or higher

318 than $66 \%$ to limit global warming to $2^{\circ} \mathrm{C}$ over the entire $21^{\text {st }}$ century, or equal to or higher than

$31950 \%$ to return to $1.5^{\circ} \mathrm{C}$ in 2100 compared to pre-industrial levels.

\section{IPCCAR5 scenarios}

321 The temperature likelihood response to 523 of these 846 Kyoto-GHG scenarios from the IPCC-

322 AR5 database was projected using the simple carbon cycle and climate model MAGICC6 ${ }^{30,31}$,

323 under a probabilistic set-up ${ }^{32}$ (data visualization available at: https://www.pik-potsdam.de/paris-

324 reality-check/ar5-scenario-explorer/). First, we selected from the database 155 scenarios that

325 have net negative emissions in 2100 . Of these 155 scenarios, a sub-selection was made of the 40

326 scenarios with a likely $(\geq 66 \%)$ chance to stay below $2^{\circ} \mathrm{C}$ throughout the $21^{\text {st }}$ century. Of these 40

327 scenarios, 2 had a more likely than not $(>50 \%)$ chance to result in a warming below $1.5^{\circ} \mathrm{C}$ in

328 2100. The number of scenarios matching each or a combination of these three criteria - negative

329 emissions in $2100,2^{\circ} \mathrm{C}(\geq 66 \%$ over $2010-2100)$ and $1.5^{\circ} \mathrm{C}(>50 \%$ in 2100$)-$ are shown in

330 Supplementary Table 1 (Supplementary Information). All the selected scenarios that have a more

331 likely than not chance of warming being below $1.5^{\circ} \mathrm{C}$ in 2100 , also have a likely chance to

332 remain below $2^{\circ} \mathrm{C}$ over the $2010-2100$ period. Only 2 of the 5 scenarios that have a more likely 
333 than not chance to be below $1.5^{\circ} \mathrm{C}$ in 2100 also have negative emissions in 2100 . The model and

334 study names of these scenarios are shown in Supplementary Table 2 (Supplementary

335 Information).

336 The ' $2{ }^{\circ} \mathrm{C}$-2030peak' scenarios have higher emissions levels than the ' $2{ }^{\circ} \mathrm{C}$-pre2020peak' but still

337 have a likely chance to limit warming to $2^{\circ} \mathrm{C}$ and do not result in higher maximal temperature

338 over the century. However, these ' $2{ }^{\circ} \mathrm{C}-2030$ peak' scenarios are from the MERGE-ETL_2011

339 model (Supplementary Information) that uses exogenous sulfate forcing ${ }^{33}$ and feature higher $\mathrm{SO}_{2}$

340 - an aerosol with a cooling effect - concentrations than other IPCC-AR5 Working Group 3

341 scenarios $^{34}$. These aerosol emissions are outside the ranges consistent with the underlying $\mathrm{CO}_{2}$

342 path $^{35}$. Moreover, the ' $2{ }^{\circ} \mathrm{C}-2030$ peak' scenarios do not peak as soon as possible, as defined in

343 Article 2 of the Paris Agreement.

$344 \quad$ Additional $1.5^{\circ} \mathrm{C}$ scenarios

345 To this selection of 40 IPCC-AR5 scenarios, we added the 37 scenarios from ref. 26 that have a

346 more likely than not $(>50 \%)$ chance to have warming below $1.5^{\circ} \mathrm{C}$ in 2100 . All of these

347 scenarios have negative emissions in 2100. These 37 scenarios are from the MESSAGE or

348 REMIND modelling frameworks and the scenario names and descriptions are available in Table

3494 of the supplementary information of ref. 26.

350 The average of all selected $1.5^{\circ} \mathrm{C}$ scenarios that peak between 2010 and 2020 is $32.6 \mathrm{GtCO}_{2} \mathrm{eq}$ in

351 2030. The UNEP gap report ${ }^{36}$ identified a $39 \mathrm{GtCO}_{2}$ eq goal for 2030 , which corresponds to the 
352 median of the $1.5^{\circ} \mathrm{C}$ scenarios (from the same source as our study) with emissions peaking in

3532020 only.

\section{4 (I)NDC scenario}

355 In addition to the selected emissions scenarios, we construct a global emissions scenario that is in

356 line with current aggregated (I)NDC targets. Between 2010 and 2030, this global ' $2{ }^{\circ} \mathrm{C}$ -

357 statedINDC' scenario follows the global emissions from the "(I)NDC factsheets"3 (for 'high-

358 ambition' or 'low-ambition' assessments, and the average of both), that include emissions

359 projections of all countries, national Land-Use, Land-Use Change and Forestry (LULUCF), and

360 international shipping and aviation ('bunker emissions') emissions until 2030. Beyond 2030, the

361 global ' $2{ }^{\circ} \mathrm{C}$-statedINDC' emissions are a 20 -year linear interpolation to reach the level of the

362 average of the global ' $2{ }^{\circ} \mathrm{C}-2030$ peak' scenarios (including LULUCF emissions). Beyond 2050,

363 the global ' $2{ }^{\circ} \mathrm{C}$-statedINDC' scenarios follows the averaged of global ' $2{ }^{\circ} \mathrm{C}-2030$ peak' scenarios.

364 The ' $2{ }^{\circ} \mathrm{C}$-statedINDC' scenario is expected to have a likely chance of limiting global warming to

$3652{ }^{\circ} \mathrm{C}$ - with the same limitations regarding SO2 concentrations as the ' $2{ }^{\circ} \mathrm{C}-2030$ peak' scenarios.

366 Indeed, the ' $2{ }^{\circ} \mathrm{C}$-statedINDC' scenario (whether it follows the INDC's 'high-ambition', 'low-

367 ambition' assessments, or the average of both) has lower emissions than the average of ' $2{ }^{\circ} \mathrm{C}$ -

368 2030peak' scenarios until 2050, and is equal to the average of ' $2{ }^{\circ} \mathrm{C}-2030$ peak' scenarios beyond

3692050 (see Fig 1). 


\section{Scenario preparation}

372 We used the Potsdam Real-time Integrated Model for the probabilistic Assessment of emission

373 Paths (PRIMAP) ${ }^{17}$ to model allocations approaches. This model contains population, GDP, and

374 GHG emissions historical and projected data from composite sources as detailed in ref. 24.

375 Kyoto-GHG emissions are aggregated following the 'SAR-GWP-100' (Global Warming

376 Potential for a 100 year time horizon) as reported in the Second Assessment Report of the

$377 \quad \mathrm{IPCC}^{37}$ and used under the UNFCCC.

378 All these global scenarios, shown in Fig. 1a, are harmonized to the PRIMAP ${ }^{17}$ database's 2010

379 emissions of $47.7 \mathrm{GtCO}_{2} \mathrm{eq}$ (including LULUCF, and international shipping and aviation

380 emissions). To do so, emissions are multiplied by a vector that is an interpolation between the

3812010 PRIMAP emissions levels divided by the respective 2010 scenarios values, and 1 in

$3822040^{24,37}$.

383 In this study, we allocate emissions of 'bunker-free' scenarios that are in line with the global

384 scenarios selected and constructed as described above, and that exclude LULUCF emissions as

385 follows. Emissions of the LULUCF sector are not considered by all parties as part of the

386 emissions scope to be negotiated. Moreover, no universal accounting method of positive or

387 negative LULUCF emissions is currently in place. Therefore, we exclude LULUCF emissions

388 from the global scenarios before allocating their emissions across countries.

389 For the IPCC-AR5 scenarios, we excluded the corresponding LULUCF emissions. For the 37

$390 \quad 1.5^{\circ} \mathrm{C}$ scenarios of ref. 26 , where no specific LULUCF emissions were available, we excluded 
391 the $\mathrm{CO}_{2}$ emissions that do not come from fossil fuels combustion. We then subtracted from these 392 IPCC-AR5 and ref. 26 scenarios international shipping and aviation emissions from the

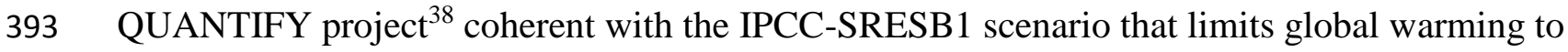
$3941.8^{\circ} \mathrm{C}$ compared to the $1980-1999$ average ${ }^{24,39}$. Shipping emissions are 3.9 times higher in 2100 395 compared to 2010 levels, and aviation emissions double over that same period, but peak in 2062. 396 While the mitigation targets agreed in Article 4 apply to all GHG, the Paris Agreement contains 397 no specific reference to bunker emissions. The lack of current policies does not leave ground to 398 project strong mitigation scenarios ${ }^{40,41}$. Lower emissions from this sector would reduce the 399 mitigation burden on all countries.

400 We also constructed a version of the ' $2{ }^{\circ} \mathrm{C}$-statedINDC' without bunker and LULUCF emissions 401 following the methodology employed to construct the ' $2{ }^{\circ} \mathrm{C}$-statedINDC' scenario that includes 402 bunker and LULUCF emissions. This bunker-free ' $2{ }^{\circ} \mathrm{C}$-statedINDC' emissions scenario is the 403 sum of all national emissions from ref. 3 over the 2010-2030 period. Beyond 2030, the bunker404 free ' $2{ }^{\circ} \mathrm{C}$-statedINDC' emissions follow a 20-year linear interpolation to reach the level of the 4052050 average of the bunker-free ' $2{ }^{\circ} \mathrm{C}-2030$ peak' scenarios (excluding bunker and LULUCF 406 emissions). Beyond 2050 , the bunker-free ' $2{ }^{\circ} \mathrm{C}$-statedINDC' scenario follows the average of the 407 bunker-free ' $2{ }^{\circ} \mathrm{C}-2030$ peak' scenarios. The bunker-free ' $2{ }^{\circ} \mathrm{C}$-statedINDC' scenario is allocated 408 across countries using our allocation framework from 2030 onwards, when countries have the 409 emission level of their (I)NDC target ${ }^{4}$. The ' $2{ }^{\circ} \mathrm{C}$-fairINDC' global scenario is equal to the ' $2{ }^{\circ} \mathrm{C}$ 410 statedINDC' scenario, both with and without LULUCF and bunker emissions. At the national 
411 level, the emissions allocation of the ' $2{ }^{\circ} \mathrm{C}$-fairINDC' scenario begins in 2010 and therefore

412 differs from the national emissions of the ' $2{ }^{\circ} \mathrm{C}$-statedINDC' scenario.

413 All these bunker-free scenarios are harmonized to the PRIMAP ${ }^{17}$ database's 2010 emissions of

$414 \quad 42.5 \mathrm{GtCO}_{2} \mathrm{eq}$ (excluding LULUCF, international shipping and aviation emissions). To do so,

415 national emissions are multiplied by a vector that is an interpolation between the 2010 PRIMAP

416 national emissions levels divided by the respective 2010 bunker-free scenarios values, and 1 in

$4172040^{24,37}$. These bunker-free scenarios, excluding LULUCF and international shipping and

418 aviation emissions are shown in Supplementary Figure 1 (Supplementary Information).

419 The allocation of the scenarios' bunker-free emissions follows the methodology and the

420 parameterization described in the supplementary information of ref. 24 . The only exception is the

421 ' $2{ }^{\circ} \mathrm{C}$-statedINDC' case whose allocation starts in 2030, starting at estimated national (I)NDC

422 levels. All other cases have emissions allocations starting in 2010 at national historical levels ${ }^{17}$.

423 The GDR allocation approach requires business-as-usual emissions projections. We use RCP8.5,

424 downscaled using the SSP2 scenario (https://tntcat.iiasa.ac.at/SspDb/) from the Shared

425 Socioeconomic Pathways framework ${ }^{42,43}$. More details are available in ref. 24 . The business-as-

426 usual emissions projections used in the ' $2{ }^{\circ} \mathrm{C}$-statedINDC' beyond 2030 national (I)NDC levels

427 case follow the growth rates of RCP8.5 over the 2030-2100 period.

428 The modelling and the parameterization of the equity approaches follow those of a previous

429 study $^{24}$. Notably, a 30-year linear transition period is implemented between national 2010

430 emissions and the allocations under the CAP and EPC approaches. Therefore, in 2030 this 
431 transition period still slightly favours countries with allocations lower than their 2010 levels -

432 usually developed countries, and slightly disfavours countries with allocations higher than their

4332010 levels. Historical emissions are accounted since 1990 under the GDR and CPC approaches.

434 The CPC approach applies a $1.5 \%$ annual discount rate to emissions before 2010 and achieves

435 equal cumulative per capita emissions in 2100. The GDR approach allocates emissions

436 reduction, compared to business-as-usual scenarios, to country’s citizens earning over $\$ 7500$ (in

437 purchase power parity) annually.

438 The distribution of regional mitigation action as represented in least-cost mitigation pathways is

439 not necessarily equitable. Our results show how pathways that achieve the global Paris

440 Agreement mitigation goals at lowest cost can be aligned with equity principles at the national

441 scale.

442 The (I)NDC assessment used in this study is an average of the 'high-ambition' and 'low-

443 ambition' cases from ref. 3, except in Fig. 3 that uses 'high-ambition' (I)NDC assessment. The

444 'high-ambition' assessment uses conditional (I)NDCs when available as well as the most

445 ambitious end of the uncertainty associated with the (I)NDC assessment (based on GDP,

446 population, energy demand projections). The 'low-ambition' assessment reflects the lower

447 ambitions end of the uncertainty associated with the assessment of unconditional (I)NDCs. The

448 assessments used in this study ${ }^{2,3}$ used in this study are based on original (I)NDCs, before their

449 conversion to NDCs. 


\section{Countries with missing data}

451 Deriving the CAP and GDR allocations requires national projections of GDP. The PRIMAP

452 database does not contain such projections for all countries due to a lack of available data.

453 Countries with some missing data ('missing countries' whose ISO-Alpha 3 country codes are:

454 'AFG', 'AGO', 'ALB', 'AND', 'ARE', 'ATG', 'COK', 'DMA', 'FSM', 'GRD', 'KIR', 'KNA', 'LIE', 455 'MCO', 'MHL', 'MMR', 'MNE', 'NIU', 'NRU', 'PLW', 'PRK', 'QAT', 'SMR', 'SSD', 'SYC', 'TUV',

456 'ZWE') are mostly developing countries whose emissions allocation could represent a significant

457 fraction of global 2030 emissions, under the CAP allocation in particular given their low GDP

458 per capita (https://www.imf.org/external/pubs/ft/weo/2015/01/weodata/download.aspx). We

459 excluded the countries with missing data from the allocations and the remaining countries share

460 the global 'bunker-free' scenarios' emissions. Figure 3 displays the aggregated conditional

461 (I)NDCs excluding these 'missing countries'. As a consequence, the mitigation gaps between the 462 aggregated (I)NDCs and the aggregated average allocations are affected by the exclusion of

463 countries' 2030 (I)NDC emissions (and is greater or smaller depending on how the sum of

464 average allocations of these countries would compare to the sum of their conditional (I)NDCs).

465 The gap between that sum of all countries' conditional (I)NDCs $-49.8 \mathrm{GtCO}_{2} \mathrm{eq}$ including the

466 'missing countries' (51.4 $\mathrm{GtCO}_{2} \mathrm{eq}$ with bunker emissions), excluding LULUCF emissions - and 467 the sum of available average allocations $-40.1 \mathrm{GtCO}_{2} \mathrm{eq}-$ would be $9.6 \mathrm{GtCO}_{2} \mathrm{eq}$ instead of 8.8

$468 \mathrm{GtCO}_{2}$ eq. As a reminder, the gap between the 'major economies' (G8 plus China) aggregated 469 conditional (I)NDCs and their aggregated allocation is of $9.6 \mathrm{GtCO}_{2} \mathrm{eq}$. The conclusions of 470 Figure 3 are still valid in this configuration. Note that the aggregate level of all 'high-ambition' 
471 (I)NDCs including LULUCF emissions (including the 'missing countries') is $49.4 \mathrm{GtCO}_{2} \mathrm{eq}$, and $472 \quad 47.8 \mathrm{GtCO}_{2}$ eq excluding bunker emissions. 
474 30. Meinshausen, M., Raper, S. C. B. \& Wigley, T. M. L. Emulating coupled atmosphere-ocean and 475 carbon cycle models with a simpler model, MAGICC6 - Part 1: Model description and calibration. Atmos. 476 Chem. Phys. 11, 1417-1456 (2011).

477 31. Meinshausen, M., Wigley, T. M. L. \& Raper, S. C. B. Emulating atmosphere-ocean and carbon 478 cycle models with a simpler model, MAGICC6 - Part 2: Applications. Atmos. Chem. Phys. 11, 1457-1471 479 (2011).

480 32. Meinshausen, M. et al. Greenhouse-gas emission targets for limiting global warming to 2 481 degrees C. Nature 458, 1158-62 (2009).

482 33. Harmsen, M. et al. How well do integrated assessment models represent non-CO2 radiative 483 forcing? Clim. Change 565-582 (2015). doi:10.1007/s10584-015-1485-0

484 34. Bernie, D. \& Lowe, J. Analysis of climate projections from the IPCC working group 3 scenario 485 database. (2014).

$486 \quad 35 . \quad$ Rogelj, J. et al. Air-pollution emission ranges consistent with the representative concentration 487 pathways. Nat. Clim. Chang. 4, 446-450 (2014).

$488 \quad 36 . \quad$ UNEP. The Emission Gap Report 2015. A UNEP Synthesis Report. (2015).

489 37. Meinshausen, M. et al. The RCP greenhouse gas concentrations and their extensions from 1765 490 to 2300. Clim. Change 109, 213-241 (2011).

491 38. Owen, B., Lee, D. S. \& Lim, L. Flying into the future: Aviation emissions scenarios to 2050.

492 Environ. Sci. Technol. 44, 2255-2260 (2010).

493 39. Solomon, S. et al. IPCC, 2007: Summary for Policymakers. In: Climate Change 2007: The Physical 494 Science Basis. Contribution of Working Group I to the Fourth Assessment Report of the 495 Intergovernmental Panel on Climate Change. (2007).

496 40. Cames, M., Graichen, J., Siemons, A. \& Cook, V. Emission Reduction Targets for International 497 Aviation and Shipping. Igarss 2014 (2015).

498 41. Anderson, K. \& Bows, A. Executing a Scharnow turn: reconciling shipping emissions with 499 international commitments on climate change. Carbon Manag. 3, 615-628 (2012).

$500 \quad 42 . \quad K C$, S. \& Lutz, W. The human core of the shared socioeconomic pathways: Population scenarios 501 by age, sex and level of education for all countries to 2100. Glob. Environ. Chang. IN PRESS, (2014). 
502 43. Crespo Cuaresma, J. Income projections for climate change research: A framework based on 503 human capital dynamics. Glob. Environ. Chang. IN PRESS, (2015). 